\title{
Heterozygous deficiency of hypoxia-inducible factor-2 $\alpha$ protects mice against pulmonary hypertension and right ventricular dysfunction during prolonged hypoxia
}

\author{
Koen Brusselmans, ${ }^{1}$ Veerle Compernolle, ${ }^{1}$ Marc Tjwa, ${ }^{1}$ Michael S. Wiesener, ${ }^{2}$ \\ Patrick H. Maxwell, ${ }^{3}$ Désiré Collen, ${ }^{1}$ and Peter Carmeliet ${ }^{1}$ \\ ${ }^{1}$ Center for Transgene Technology and Gene Therapy, Flanders Interuniversity Institute for Biotechnology, \\ Katholieke Universiteit Leuven, Leuven, Belgium \\ ${ }^{2}$ Department of Nephrology and Medical Intensive Care, Klinikum Charité, Campus Virchow, Humboldt University, \\ Berlin, Germany \\ ${ }^{3}$ Renal Section, Imperial College of Science, Technology and Medicine, Hammersmith Campus, London, United Kingdom
}

\begin{abstract}
Chronic hypoxia induces pulmonary vascular remodeling, leading to pulmonary hypertension, right ventricular hypertrophy, and heart failure. Heterozygous deficiency of hypoxia-inducible factor-1 $\alpha$ (HIF-1 $\alpha$ ), which mediates the cellular response to hypoxia by increasing expression of genes involved in erythropoiesis and angiogenesis, has been previously shown to delay hypoxia-induced pulmonary hypertension. HIF- $2 \alpha$ is a homologue of HIF- $1 \alpha$ and is abundantly expressed in the lung, but its role in pulmonary hypertension remains unknown. Therefore, we analyzed the pulmonary response of WT and viable heterozygous HIF-2 $\alpha$-deficient $\left(H i f 2 \alpha^{+/-}\right)$mice after exposure to $10 \% \mathrm{O}_{2}$ for 4 weeks. In contrast to WT mice, $H i f 2 \alpha^{+/-}$mice were fully protected against pulmonary hypertension and right ventricular hypertrophy, unveiling a critical role of HIF- $2 \alpha$ in hypoxia-induced pulmonary vascular remodeling. Pulmonary expression levels of endothelin-1 and plasma catecholamine levels were increased threefold and 12-fold respectively in WT but not in $\mathrm{Hif} 2 \mathrm{\alpha}^{+/-}$mice after hypoxia, suggesting that HIF-2 $\alpha$-mediated upregulation of these vasoconstrictors contributes to the development of hypoxic pulmonary vascular remodeling.
\end{abstract}

J. Clin. Invest. 111:1519-1527 (2003). doi:10.1172/JCI200315496.

\section{Introduction}

Pulmonary hypertension is a formidable health problem, as it often leads to right ventricular (RV) hypertrophy and heart failure $(1,2)$. Current treatment includes the administration of oxygen, bronchodilators, vasodilators (e.g., prostacyclin, NO, and endothelin-1 antagonists), and, eventually, mechanical ventilation (2-4). However, since oxygenation and vasodilatation merely delay the progression of this disease, a better understanding of its pathogenesis is required (2). The pathophysiology of hypoxic pulmonary hypertension is complex and poorly understood. It is characterized by increased levels of the vasoconstrictors angiotensin II and endothelin-1 (ET-1),

Received for publication March 21, 2002, and accepted in revised form March 11, 2003.

Address correspondence to: Peter Carmeliet, Center for Transgene Technology and Gene Therapy, Flanders Interuniversity Institute of Biotechnology, Katholieke Universiteit Leuven, Gasthuisberg, Herestraat 49, B-3000 Leuven, Belgium.

Phone: 32-16-34-57-72; Fax: 32-16-34-59-90; E-mail: peter.carmeliet@med.kuleuven.ac.be.

Conflict of interest: The authors have declared that no conflict of interest exists.

Nonstandard abbreviations used: right ventricular (RV); endothelin-1 (ET-1); hypoxia-inducible factor- $1 \alpha$ (HIF-1 $\alpha)$; hypoxia-response element (HRE); internal elastic lamina (IEL); external elastic lamina (EEL); smooth muscle cell (SMC); norepinephrine (NE). impaired production of the vasodilators $\mathrm{NO}$ and prostacyclin, and an unbalanced production of factors affecting growth, migration, and differentiation of VSMCs, including FGF-2, PDGF-B, TGF- $\beta$, IGF-I and -II, and EGF $(5,6)$. As a result, peripheral, normally nonmuscular arteries become muscularized, and the media and adventitia enlarge (5-7). Loss of eNOS (8) or prostacyclin receptor (9) aggravates hypoxic pulmonary vascular disease, whereas ET-1 receptor blockade (4), overexpression of prostacyclin (10), and gene transfer of iNOS (11) reduce hypoxia-induced pulmonary hypertension. In addition, deficiency of the serotonin transporter, a pulmonary VSMC mitogen that is upregulated during hypoxia, also attenuates hypoxic pulmonary hypertension (12). Furthermore, serine elastase, plasminogen, and MMPs have been implicated in growth and migration of VSMCs via degradation of the ECM and release of mitogens or differentiation factors (13). Proteinases are involved in the pathology of pulmonary hypertension, since mice deficient in plasminogen or urokinase-type plasminogen activator are partially protected against pulmonary vascular remodeling (14). Very recently, gene transfer of VEGF was also shown to reduce pulmonary hypertension in rats (15).

Hypoxia-inducible factor- $1 \alpha$ (HIF-1 $\alpha)$ is a key regulator in the cellular adaptation to hypoxia (16). During hypoxia, HIF- $1 \alpha$ upregulates the expression of a number of genes involved in erythropoiesis, glycolysis, and angiogenesis by binding, as a heterodimer with HIF-1 $\beta$, 
to a hypoxia-response element (HRE) in the promoter of these target genes $(16,17)$. Loss of HIF- $1 \alpha$ or HIF- $1 \beta$ impaired gene expression in response to hypoxia and/or hypoglycemia and caused embryonic lethality around embryonic day $10.5(16,17)$. Recently, a novel homologue, HIF-2 $\alpha$ (also known as EPAS1 [ref. 18], HLF [ref. 19], or HRF [ref. 20]), was identified, which also binds as a heterodimer with HIF- $1 \beta$ to the HRE in the promoter of target genes. Gene-inactivation studies revealed a role of HIF- $2 \alpha$ in cardiovascular development and angiogenesis in the embryo $(21,22)$, but its role in adult pathologies remains unknown.

HIF-1 $\alpha$ was recently demonstrated to be involved in the pulmonary response to chronic hypoxia, since pulmonary hypertension was delayed in heterozygous deficient $\mathrm{Hifl}^{+/ /} \mathrm{m}^{+}$mice (23). In addition, Hif1 $\alpha^{+/-}$pulmonary arterial myocytes showed impaired electrophysiological responses to chronic hypoxia (24). Although HIF- $2 \alpha$ is abundantly expressed in the lung $(19,20,25)$, its role in pulmonary hypertension has thus far not been studied. We previously inactivated the Hif $2 \alpha$ gene in embryonic stem cells (26) and used them to generate transgenic mice (25). Since homozygous deficient Hif $2 \mathrm{\alpha}^{-/}$mice died during gestation or immediately after birth $(21,22,25)$, viable heterozygous $H i f 2 \alpha^{+/-}$mice were used in the present study to analyze the role of HIF- $2 \alpha$ during pulmonary hypertension and vascular remodeling.

\section{Methods}

Animal protocol. Animal experiments were approved by the institutional review board and were performed as previously described (14), according to the guidelines for animal experiments of the NIH. Eight-week-old mice (littermates; mixed-background Swiss/129Sv) were weighed and placed in a tightly sealed chamber under normobaric hypoxia $\left(10 \% \mathrm{O}_{2}\right)$, which was maintained by a continuous inflow of $2 \mathrm{l} / \mathrm{min} \mathrm{N}_{2}$ and 2 $1 /$ min normal air $\left(21 \% \mathrm{O}_{2}\right)$. Control mice were kept in normal air $\left(21 \% \mathrm{O}_{2}\right)$. After exposure to hypoxia for the indicated period, mice were weighed and immediately used for determination of RV hypertrophy, hematocrit, plasma catecholamine levels, gene expression, and histology. For the hemodynamic measurements, mice were first equilibrated to room air for 1 hour.

Hemodynamic measurements after exposure to chronic bypoxia. Hemodynamic measurements were performed as previously described (14). Mice were first equilibrated by returning them to room air for 1 hour, to avoid acute vasomotor responses $(11,23)$, and were then anesthetized with urethane $(1.4 \mathrm{mg} / \mathrm{kg})$. While the mice were ventilated (Minivent 845; Hugo Sachs Elektronik, March-Hugstetten, Germany; 150 strokes per minute, volume $250 \mu \mathrm{l}$ ), RV pressures were measured via transthoracic puncture using a $1.4 \mathrm{~F}$ high-fidelity pressure micromanometer (SPR-671; Millar Instruments Inc., Houston, Texas, USA) at controlled normal body temperatures. Manometer reference settings were calibrated before each measurement. Correct manometer position in the right ventricle was verified by pressure readings and confirmed by postmortem examination. After hemodynamic stabilization, pressure measurements were amplified (Siemens Pressure Amplifier 863; Siemens-Elema AB, Solna, Sweden) and unfiltered digitalized (Dataq DA Convert DI-205; Dataq Instruments Inc., Akron, Ohio, USA) (sampling rate 2,000 Hz). Digital files were recorded and analyzed (WinDaq software; Dataq Instruments Inc.) as previously described (14). For each measurement, an average of ten sequential beats was calculated. Contractile performance indices included maximal isovolumetric rate of development of ventricular pressure $\left(\mathrm{dP} / \mathrm{dt}_{\max }\right)$ and contractility $\left(\mathrm{dP} / \mathrm{dt}_{\max } \mathrm{P}\right)$. We calculated $\tau$, the time constant of ventricular relaxation during isovolumic diastole, by fitting the decay of $\mathrm{RV}$ pressure (from $\mathrm{dP} / \mathrm{dt}_{\mathrm{min}}$ ) to a monoexponential equation assuming a zero asymptote: $P(t)=P(0) \cdot \mathrm{e}^{-t / \tau}(27)$. Functional assessment of the right ventricle in the setting of chronic pulmonary hypertension was performed as described previously (28).

Hemodynamic responses of normoxic mice to acute bypoxia and to agonists. Normoxic mice were anesthetized with urethane, ventilated, and maintained at controlled normal body temperature. Calibration of $1.4 \mathrm{~F}$ micromanometer reference settings was performed before each measurement. Introduction of the manometer was performed as previously described (29). Briefly, the pressure catheter was introduced into the RV cavity via the right jugular vein. Continuous recording of pressure parameters was performed during initial ventilation with room air (15 minutes), and during ventilation with a hypoxic gas mixture $\left(7 \% \mathrm{O}_{2}, 93 \% \mathrm{~N}_{2} ; 20\right.$ minutes) or after agonist administration. Acute hypoxic vasoconstriction was defined as the change in RV systolic pressure, expressed as percentage of base-line. The vasodepressor response was evaluated as previously described (30). Briefly, vasoconstriction was induced by i.v. injection of prostaglandin $\mathrm{F}_{2 \alpha}(0.3 \mu \mathrm{g} / \mathrm{kg})$. After 3 minutes, bradykinin $(1 \mu \mathrm{g} / \mathrm{kg})$ was injected i.v., and vasodepressor responses, defined as the RV systolic pressure at injection of bradykinin minus the RV systolic pressure 3 minutes later, were measured.

Hematocrit and plasma catecholamine analysis. Blood samples were collected from the vena cava, and hematocrit was analyzed using an automated cell counter (Cell-Dyn 1330; Abbott Laboratories, Abbott Park, Illinois, USA) (14). Plasma norepinephrine levels were quantified by HPLC in the University Hospital Laboratory (Katholieke Universiteit Leuven, Leuven, Belgium) as previously described (22).

$R V$ bypertrophy measurement. Hearts were dissected, and the RV wall was removed from the left ventricle and septum after removal of the atria (14). Ventricles were dried at $55^{\circ} \mathrm{C}$ (until weight difference between two consecutive days was less than $0.1 \mathrm{mg}$ ) and weighed. Results were expressed as the ratio of right ventricle weight to left ventricle plus septum weight $[\mathrm{RV} /(\mathrm{LV}+\mathrm{S})]$ or as the ratio of right ventricle weight to total body weight (RV/B). 
Histological analysis. As described previously (14), we performed tissue preparations; Hart's elastin staining, for visualization of internal and external elastic lamina (IEL and EEL); staining of smooth muscle cells (SMCs) with mouse antibodies against murine SMC $\alpha$-actin; and staining of endothelial cells with rabbit antibodies against thrombomodulin. To assess pulmonary vascular remodeling, we counted the number of nonmuscularized (only IEL), partially muscularized (IEL plus incomplete EEL), and fully muscularized (IEL and complete EEL) peripheral vessels that were located distally to the bronchi. Vessel numbers were quantified using the Quantimet Q600 imaging system (Leica Imaging Systems Ltd., Cambridge, United Kingdom) and expressed per 100 alveoli $(14,31)$. Wall thickness of completely muscularized pulmonary arterioles (diameter less than $80 \mu \mathrm{m}$ ) was calculated as the percentage of the diameter of the EEL minus the diameter of the IEL divided by the diameter of the EEL $(14,31)$. Capillary density and intercapillary distance were measured as previously described (14), using the Quantimet Q600 imaging system.

Gene expression analysis. Protein extraction and Western blot analysis were performed as previously described (17, 26). Briefly, frozen tissues were homogenized in extraction buffer, and extracts were quantified with the BioRad DC protein assay (Bio-Rad Laboratories $\mathrm{GmbH}$, Munich, Germany). Fifty micrograms of total protein was separated by 6\% SDS-PAGE, transferred onto Immobilon-P membranes (Millipore Corp., Bedford, Massachusetts, USA), and incubated with antibodies against eNOS (Calbiochem-Novabiochem Corp., San Diego, California, USA) or against HIF- $1 \alpha$ or HIF- $2 \alpha$ (previously generated [ref. 32]). Detection was performed by chemiluminescence (SuperSignal West Dura; Pierce Chemical Co., Rockford, Illinois, USA) with HRP-conjugated secondary antibodies. ET-1 protein levels were determined by ELISA (Immuno-Biological Laboratories Hamburg, Hamburg, Germany). RNA extractions from lungs and hearts and TaqMan quantitative real-time RT-PCR (Applied Biosystems, Lennik, Belgium) were performed as previously described (26). Gene expression was determined as the amount of mRNA copies per 100 mRNA copies of the HPRT gene (hypoxanthine-guanine phosphoribosyl transferase), which was used as an internal control. We used the following forward $(F)$ and reverse $(\mathrm{R})$ primers, and probes $(\mathrm{P})$ labeled with fluorescent dyes (FAM or JOE) and quenchers (TAMRA): for HPRT, F, 5'-TTATCAGACTGAAGAGCTACTGTAATGATC3', R, 5'-TTACCAGTGTCAATTATATCTTCAACAATC-3', and P, 5'-JOE-TGAGAGATCATCTCCACCAATAACTTTTATGTCCC-TAMRA-3'; for eNOS, F, 5'-AGCCCGGGACTTCATCAATC-3', R, 5'-TGAAGCCGCTGCTCATGAG-3', and P, 5' FAM-ACTATAACTCCATCAAAAGGAGTGGCTCCCAG-TAM RA-3'; for ET-1, F, 5' -CTTCTGCCACCTGGACATCA-3', R, $5^{\prime}$-CTCCCAGTCCATACGGTACGA-3', and P, 5'-FAMCTGGGTCAACACTCCCGAGCGC-TAMRA-3'; for PDGF- $B$, F, 5'-CGGTCCAGGTGAGAAAGATTG-3', R, 5'-CGTCTTGGCTCGCTGCTC-3' ${ }^{\prime}$, and P, 5' -FAM-CCCATCTTCAAGAAG-
GCCACAGTGACCT-TAMRA-3'; for $H I F-1 \alpha, \mathrm{F}, 5^{\prime}$-TGAGCTCACATCTTGATAAAGCTTCT-3', R, 5'-GGGCTTTCAGATAAAAACAGTCCAT-3', and P, 5'-FAM-AGACCACCGGCATCCAGAAGTTTTCTCA-TAMRA-3', for HIF-2 $\alpha$, F, 5'-CCTGGCCATCAGCTT-3'， R， 5'-CTGGTCGGCCTCAGCTTC- $3^{\prime}$, and P, 5'-FAM-CACATAAGCTCCTCAGTCTGCTCTGA-TAMRA-3'.

Statistical analysis. Data are expressed as mean \pm SEM. Comparisons of values were made using a nonparametric Mann-Whitney $U$ test.

\section{Results}

Generation of heterozygous HIF- $2 \alpha$-deficient (Hif $2 \alpha^{+/-}$) mice. To study the role of HIF- $2 \alpha$ in vivo, we previously inactivated the HIF-2 $\alpha$ gene in embryonic stem cells by homologous recombination (26) with deletion of the second exon, encoding the basic helixloop-helix domain, which is essential for DNA binding and dimerization $(16,18,22)$. Transgenic mice lacking a single HIF-2 $\alpha$ allele $\left(H i f 2 \alpha^{+/-}\right)$were generated using diploid embryo aggregation and subsequent breeding of high-percentage chimeras as previously described (25). Hif $2 \alpha^{+/-}$mice were viable and healthy and, upon macroscopic and microscopic analysis, did not exhibit obvious vascular abnormalities in the heart (see below) and kidneys (afferent and efferent arterioles per longitudinal kidney section: $170 \pm 4$ in $H I F-2 \alpha^{+/+}$mice - hereafter referred to as WT mice and $168 \pm 10$ in Hif2 $\alpha^{+/-}$mice; $n=3-5 ; P=\mathrm{NS}$ ). Half of the Hif $2 \alpha^{/-}$embryos died during gestation, while the remaining Hif $2 \alpha^{/-}$mice died at birth, consistent with previous reports $(21,22,25)$.

Expression of HIF- $1 \alpha$ and HIF- $2 \alpha$ was analyzed in WT and Hif $2 \alpha^{+/-}$mice. HIF- $2 \alpha$ transcript levels, expressed as mRNA copy number per $100 \mathrm{HPRT}$ mRNA copies, were reduced by $50 \%$ in Hif $2 \alpha^{+/-}$mice in the lungs $(23 \pm 4$ and $20 \pm 2$ in WT mice vs. $12 \pm 2$ and $11 \pm 1$ in Hif $2 \alpha^{+/-}$mice in normoxia and hypoxia, respectively; $n=6 ; P<0.05)$ and in the heart $(3.3 \pm 0.7$ and $3.0 \pm 0.5$ in WT mice vs. $1.7 \pm 0.3$ and $1.6 \pm 0.4$ in Hif $2 \alpha^{+/-}$mice in normoxia and hypoxia, respectively; $n=6 ; P<0.05)$. Heterozygous loss of HIF- $2 \alpha$ was not compensated by HIF- $1 \alpha$, since HIF- $1 \alpha$ mRNA levels (mRNA copy number per 100 HPRT mRNA copies) were comparable in both genotypes in the lungs (16 \pm 2 and $12 \pm 1$ in WT mice vs. $13 \pm 1$ and $13 \pm 3$ in Hif $2 \alpha^{+/-}$mice in normoxia and hypoxia, respectively; $n=6 ; P=\mathrm{NS})$ and in the heart (55 \pm 3 and $39 \pm 5$ in WT mice vs. $48 \pm 9$ and $44 \pm 3$ in Hif $2 \alpha^{+/-}$mice in normoxia and hypoxia, respectively; $n=6 ; P=\mathrm{NS}$ ). Western blot analysis revealed that both normoxic and hypoxic pulmonary HIF- $2 \alpha$ protein levels were significantly decreased in Hif $2 \alpha^{+/-}$mice compared with WT mice (Figure 1a). HIF-1 $\alpha$ protein was undetectable in both normoxic and hypoxic lungs (data not shown), consistent with previous reports (23).

Hif $2 \alpha^{+/-}$mice survive long-term exposure to severe bypoxia. To study the role of HIF- $2 \alpha$ in the response to chronic hypoxia, 8-week-old WT and Hif $2 \alpha^{+/-}$littermates were 
a

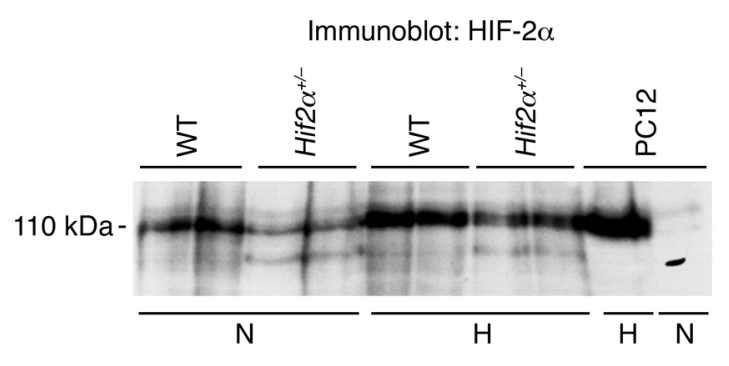

C

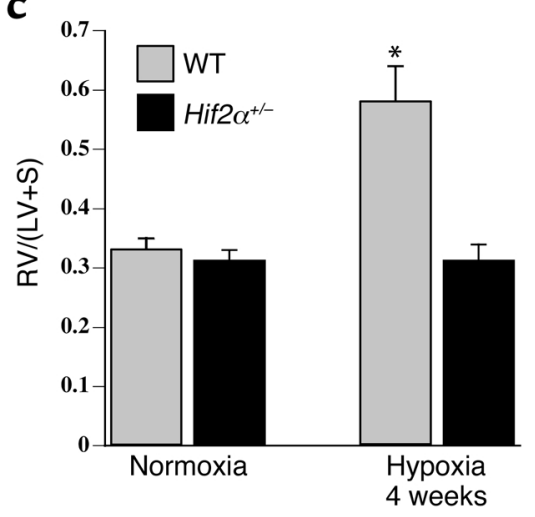

b

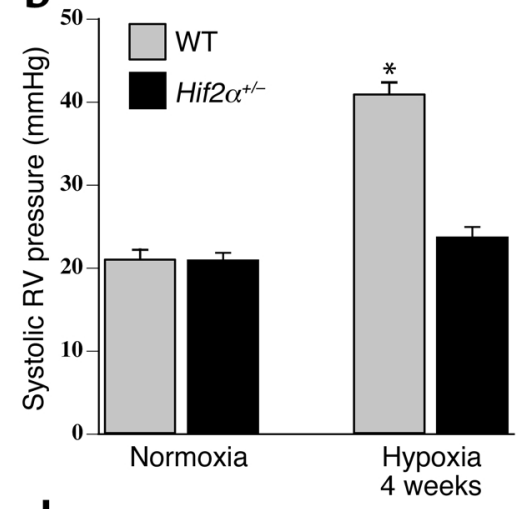

d

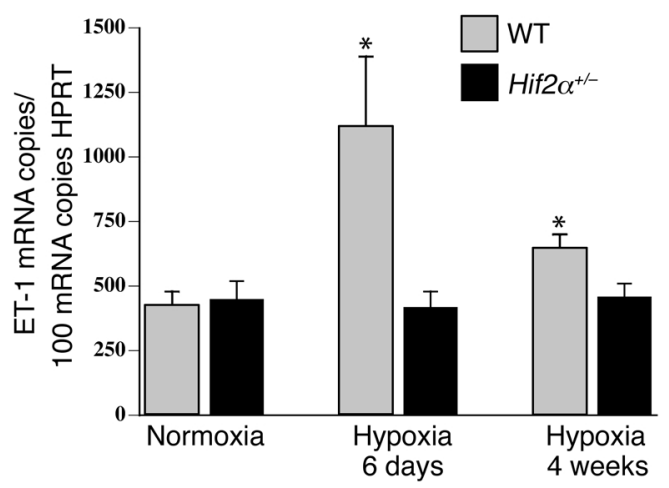

Figure 1

(a) Western blot analysis showed that pulmonary HIF-2 $\alpha$ protein levels were decreased in Hif $2 \alpha^{+/-}$mice compared with WT mice after normoxia $(\mathrm{N})$ and after 1 week of hypoxia $(\mathrm{H})$. Extracts from PC12 cells, exposed to normoxia or hypoxia (1\% oxygen, 4 hours) as previously described $(17,26)$, were used as controls. (b) Systolic RV pressures in WT and Hif2 $\alpha^{+/-}$mice under normoxia or after hypoxic exposure. Hemodynamic analysis revealed no differences in RV pressure under normoxia; however, WT mice showed increased RV pressure after 4 weeks of hypoxia, but $H i f 2 \alpha^{+/-}$mice did not. (c) RV hypertrophy analysis in WT and Hif $2 \alpha^{+/-}$mice revealed no differences under normoxic conditions. After hypoxic exposure for 4 weeks, the ratio of the mass of the right ventricle to the mass of the left ventricle plus septum $[\mathrm{RV} /(\mathrm{LV}+\mathrm{S})]$ was increased in WT mice but not in Hif2 $\alpha^{+/-}$mice. (d) Pulmonary ET-1 transcript levels were increased in WT mice after exposure to chronic hypoxia for 6 days and were still elevated after 4 weeks of hypoxia. In contrast, chronic hypoxia failed to induce ET- 1 expression in lungs of Hif $2 \alpha^{+/-}$mice. Data represent means \pm SEM of systolic RV pressure ( $\left.\mathrm{mmHg} ; n=4-7\right)(\mathbf{b})$, of the ratio of the mass of the right ventricle to the mass of the left ventricle plus septum $[\mathrm{RV} /(\mathrm{LV}+\mathrm{S}) ; n=6-7](\mathrm{c})$, and of the ET-1 mRNA copy number per 100 copies of HPRT $(n=5-6)(d) .{ }^{*}$ Statistically significant $(P<0.05)$ vs. control (WT, normoxia).

housed under normobaric hypoxia $\left(10 \% \mathrm{O}_{2}\right)$ for 4 weeks. Control groups of both genotypes were maintained in normal air $\left(21 \% \mathrm{O}_{2}\right)$. At the start of the experiment, mice of both genotypes appeared healthy, actively moved in their cages, and had comparable body weights (about $26 \mathrm{~g}$ ). After 4 weeks in normoxia, WT mice gained more weight than $\mathrm{Hif} 2 \mathrm{\alpha}^{+/-}$mice $(22 \% \pm 3 \%$ for WT mice vs. $10 \% \pm 3 \%$ for Hif $2 \alpha^{+/-}$mice; $n=6-8$; $P=0.04)$. When exposed to hypoxia, most WT mice became immobile and lost $29 \% \pm 2 \%$ of their body weight, but none of the mice died after 4 weeks of hypoxia. In contrast, $\mathrm{Hif} 2 \mathrm{\alpha}^{+/-}$mice did not exhibit any signs of discomfort, behaved normally, moved around actively, and lost only $16 \% \pm 2 \%$ of their body weight after 4 weeks of hypoxia $(P<0.001$ vs. WT mice; $n=15-17)$.

Hif $2 \alpha^{+/-}$mice are protected against pulmonary hypertension. No genotypic differences in systolic RV pressure were observed in normoxia (Figure 1b). Chronic hypoxia increased the systolic RV pressure in WT mice but, remarkably, not in $H i f 2 \alpha^{+/-}$mice (Figure 1b).
Additional hemodynamic measurements demonstrated that exposure of normoxic mice to acute hypoxia $\left(7 \% \mathrm{O}_{2}\right)$ for 20 minutes caused a similar increase in systolic RV pressure in WT mice $(25 \% \pm 9 \%$; $n=5)$ and $\mathrm{Hif} 2 \alpha^{+/-}$mice $(29 \% \pm 7 \% ; n=4 ; P=\mathrm{NS})$. In addition, bradykinin-induced vasodepressor responses were also comparable in WT and $\mathrm{Hif} 2 \mathrm{\alpha}^{+/-}$ mice $(2.0 \pm 0.2 \mathrm{mmHg}$ in WT mice vs. $2.2 \pm 0.2 \mathrm{mmHg}$ in Hif $2 \alpha^{+/-}$mice; $n=4 ; P=\mathrm{NS}$ ). These data indicate that acute vasoconstriction and vasodepressor responses were comparable in WT and Hif $2 \alpha^{+/-}$mice and that protection of Hif $2 \alpha^{+/-}$mice against pulmonary hypertension was not attributable to differences in acute vasomotor responses. Taken together, these results suggest that any possible additional increase of $\mathrm{RV}$ pressure due to hypoxia-induced vasoconstriction may indeed have also contributed to the RV hypertrophy in WT mice but had, obviously, no effect on pulmonary vascular remodeling and RV hypertrophy in Hif $2 \alpha^{+/-}$mice. 
RV contractility, measured by the maximal $\mathrm{dP} / \mathrm{dt}$ corrected for the $\mathrm{RV}$ pressure $\left(\mathrm{dP} / \mathrm{dt}_{\max } \mathrm{P}\right)$, was comparable in both genotypes in normoxia $\left(180 \pm 32 \mathrm{~s}^{-1}\right.$ in WT mice vs. $160 \pm 29 \mathrm{~s}^{-1}$ in Hif $2 \alpha^{+/-}$mice; $\left.n=4-5 ; P=\mathrm{NS}\right)$. After 4 weeks of hypoxia, RV contractility tended to be impaired in WT mice $\left(110 \pm 27 \mathrm{~s}^{-1} ; n=4 ; P=\mathrm{NS}\right.$ vs. normoxic WT mice), while it was improved in $\mathrm{Hif} 2 \mathrm{\alpha}^{+/}$mice $\left(290 \pm 41 \mathrm{~s}^{-1} ; n=6 ; P<0.02\right.$ vs. normoxic WT and Hif $2 \alpha^{+/-}$mice). RV diastolic function, evaluated by measuring the relaxation time constant $\tau$, was comparable in both genotypes in normoxia $(\tau=9 \pm 1 \mathrm{~ms}$ in WT mice vs. $7 \pm 1 \mathrm{~ms}$ in Hif $2 \alpha^{+/-}$mice; $n=4-5 ; P=\mathrm{NS}$ ). In contrast, after 4 weeks of hypoxia, RV relaxation was significantly impaired in WT but not in $\mathrm{Hif} 2 \alpha^{+/-}$mice $\left(\tau=17 \pm 5 \mathrm{~ms}\right.$ in WT mice vs. $6 \pm 1 \mathrm{~ms}$ in Hif $2 \alpha^{+/-}$mice; $n=4-6 ; P=0.01)$. Heart rates were comparable in WT and $H$ if $2 \alpha^{+/-}$mice in normoxia and after exposure to hypoxia (data not shown).

Hif $2 \alpha^{+/-}$mice are protected against $R V$ bypertropby. To evaluate RV hypertrophy, the weights of the RV and of the left ventricle plus septum $(\mathrm{LV}+\mathrm{S})$ were determined. No genotypic differences were observed in the $\mathrm{RV} /(\mathrm{LV}+\mathrm{S})$ weight ratio in normoxia (Figure $1 \mathrm{c})$. After 4 weeks of hypoxia, the $\mathrm{RV} /(\mathrm{LV}+\mathrm{S})$ weight ratio increased in WT but not in Hif2 $\alpha^{+/-}$mice (Figure 1c). Similar findings were obtained when the RV weight was normalized for the total body weight (B). Whereas no differences in the $\mathrm{RV} / \mathrm{B}$ weight ratio were observed in normoxia $(0.25 \pm 0.02 \mathrm{mg} / \mathrm{g}$ in WT mice vs. $0.24 \pm 0.01 \mathrm{mg} / \mathrm{g}$ in Hif $2 \alpha^{+/-}$mice; $\left.n=7-10 ; P=\mathrm{NS}\right)$, the $\mathrm{RV} / \mathrm{B}$ weight ratio was higher in WT than in Hif $2 \alpha^{+/-}$ mice after hypoxia $(0.44 \pm 0.03 \mathrm{mg} / \mathrm{g}$ in WT mice vs. $0.27 \pm 0.02 \mathrm{mg} / \mathrm{g}$ in Hif $2 \alpha^{+/-}$mice; $\left.n=6-7 ; P=0.001\right)$. As a result of the hypoxia-induced RV hypertrophy in WT mice, significant changes in the coronary vasculature developed in the RV myocardial wall: the intercapillary distance enlarged $(11 \pm 0.3 \mu \mathrm{m}$ in normoxia vs. $14 \pm 0.1 \mu \mathrm{m}$ in hypoxia; $n=5 ; P<0.05)$, while the capillary density decreased (number of capillaries/ $\mathrm{mm}^{2}: 7,200 \pm 240$ in normoxia vs. 5,600 \pm 390 in hypoxia; $n=5 ; P<0.05)$. Since there was no compensatory angiogenesis, as evidenced by the normal capillary/cardiomyocyte ratio $(1.2 \pm 0.08$ in normoxia vs. $1.1 \pm 0.04$ in hypoxia; $n=5 ; P=\mathrm{NS})$, the hypertrophic cardiomyocytes may have suffered some degree of ischemia. In contrast, no such signs of vascular insufficiency were detectable in Hif $2 \alpha^{+/-}$mice (intercapillary distance: $12 \pm 0.3 \mu \mathrm{m}$ in normoxia vs. $11 \pm 0.3 \mu \mathrm{m}$ in hypoxia; capillaries $/ \mathrm{mm}^{2}: 7,000 \pm 310$ in normoxia vs. 7,600 \pm 410 in hypoxia; capillary/cardiomyocyte ratio: $1.1 \pm 0.05$ in normoxia vs. $1.2 \pm 0.08$ in hypoxia; $n=5 ; P=\mathrm{NS}$ ).

Lack of pulmonary vascular remodeling in Hif $2 \alpha^{+/-}$mice. Since pulmonary hypertension is often associated with vascular remodeling of pulmonary arteries $(5,6)$, we investigated whether HIF-2 $\alpha$ affected pulmonary vascular remodeling. Counting of vessels at the level of alveoli and alveolar ducts after elastin staining revealed that the densities of nonmuscularized vessels (containing only an IEL) or partially muscularized vessels (containing an IEL plus an incomplete EEL) were comparable in WT and Hif $2 \alpha^{+/-}$mice in normoxia (Table 1 ). After 4 weeks of hypoxia, WT mice had more thick-walled muscularized vessels containing an IEL and a complete EEL (Table 1). In contrast, vascular remodeling failed to occur in hypoxic Hif $2 \alpha^{+/-}$mice, in which the fraction of muscularized vessels with an IEL and a complete EEL was comparable to that of normoxic WT and Hif $2 \alpha^{+/-}$mice (Table 1; Figure 2, a-e). The wall thickness of completely muscularized pulmonary arterioles, measured as the percentage of the EEL diameter minus the IEL diameter divided by the EEL diameter, was comparable in both genotypes in normoxia $\left(7.6 \% \pm 0.5 \%\right.$ in WT mice vs. $8.0 \% \pm 0.5 \%$ in $\mathrm{Hif}_{2} \alpha^{+/-}$ mice; $n=5 ; P=\mathrm{NS})$. Hypoxia increased the wall thickness of completely muscularized arterioles in WT mice but not in Hif $2 \alpha^{+/-}$mice $(16 \% \pm 0.4 \%$ in WT mice vs. $7.4 \% \pm 0.2 \%$ in $H i f 2 \alpha^{+/-}$mice; $\left.n=5 ; P=0.02\right)$. The genotypic differences in vascular remodeling were confirmed by immunostaining for SMC $\alpha$-actin on lung sections. Compared with Hif $2 \alpha^{+/-}$mice, WT mice contained significantly more fully muscularized vessels that were completely surrounded by SMCs after hypoxic exposure. In Hif $2 \alpha^{+/-}$mice, most of the pulmonary vessels were only partially surrounded by SMCs after hypoxic exposure (Table 1; Figure 2, f-j).

Normal hematocrit levels in Hif $2 \alpha^{+/-}$mice. Hematocrit levels were comparable in WT and Hif $2 \alpha^{+/-}$mice in normoxia $\left(36 \% \pm 1 \%\right.$ in WT mice vs. $34 \% \pm 1 \%$ in $H$ if $2 \alpha^{+/-}$

\section{Table 1}

Hypoxia-induced pulmonary vascular remodeling

\begin{tabular}{|c|c|c|c|c|}
\hline & \multicolumn{2}{|c|}{ Normoxia } & \multicolumn{2}{|c|}{ Hypoxia } \\
\hline & WT & $H i f 2 \alpha^{+/-}$ & WT & $H i f 2 \alpha^{+/-}$ \\
\hline $\begin{array}{l}\text { Single IEL } \\
\text { IEL + incomplete EEL } \\
\text { IEL + complete EEL } \\
\text { Total }\end{array}$ & $\begin{aligned} 1.9 & \pm 0.09 \\
0.98 & \pm 0.06 \\
0.19 & \pm 0.03 \\
3.0 & \pm 0.06\end{aligned}$ & $\begin{array}{r}2.0 \pm 0.11 \\
1.0 \pm 0.04 \\
0.15 \pm 0.01 \\
3.2 \pm 0.14\end{array}$ & $\begin{array}{c}0.98 \pm 0.06^{\mathrm{A}} \\
1.1 \pm 0.06 \\
0.73 \pm 0.11^{\mathrm{A}} \\
2.8 \pm 0.16\end{array}$ & $\begin{array}{r}1.9 \pm 0.07 \\
0.88 \pm 0.09 \\
0.17 \pm 0.02 \\
2.9 \pm 0.13\end{array}$ \\
\hline $\begin{array}{l}\text { Partial SMC coverage } \\
\text { Complete SMC coverage }\end{array}$ & $\begin{array}{r}1.3 \pm 0.05 \\
0.65 \pm 0.06\end{array}$ & $\begin{array}{r}1.3 \pm 0.10 \\
0.60 \pm 0.12\end{array}$ & $\begin{array}{l}1.2 \pm 0.10 \\
1.4 \pm 0.09^{\mathrm{A}}\end{array}$ & $\begin{array}{r}1.2 \pm 0.04 \\
0.66 \pm 0.02\end{array}$ \\
\hline
\end{tabular}

The data represent means $\pm \operatorname{SEM}(n=6)$ of the number of vessels per 100 alveoli that contained a single IEL (nonmuscularized), an IEL and an incomplete EEL (partially muscularized), or an IEL and a complete EEL (fully muscularized), and means $\pm \operatorname{SEM}(n=6)$ of the number of vessels per 100 alveoli that were partially covered by SMCs (partially muscularized) or completely covered by SMCs (fully muscularized). AStatistically significant $(P<0.05)$ vs. control (WT, normoxia). 


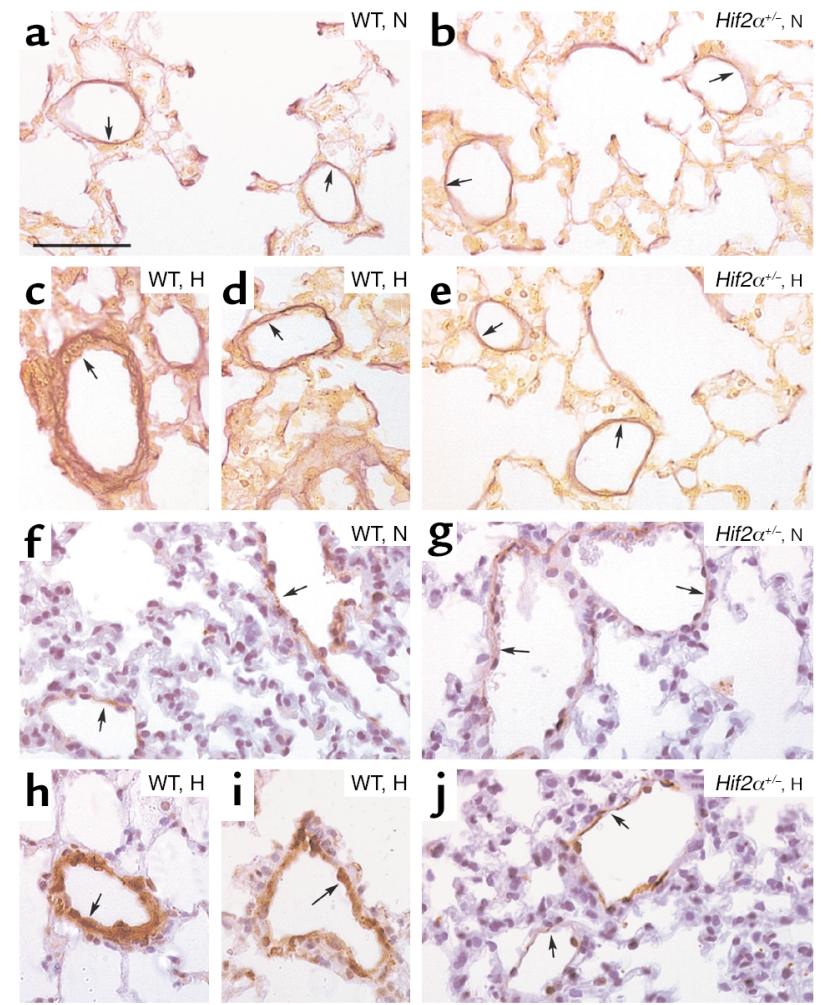

Figure 2

(a-e) Hart's elastin staining revealed the presence of vessels, located distally to the bronchi, at the level of alveoli and alveolar ducts, that contained only an IEL (or an IEL plus an incomplete EEL) (arrows) in lungs of normoxic (N) WT (a) and Hif2 $\alpha^{+/-}$mice (b). Lungs of hypoxic $(H) W T$ mice showed the presence of thick-walled vessels containing both an IEL and a complete EEL (arrows) (c and $\mathbf{d}$ ), whereas no hypoxia-induced vascular remodeling occurred in $\mathrm{Hif} 2 \alpha^{+/-}$mice (arrows) (e). (f-j) SMC $\alpha$-actin staining shows the presence of partially muscularized peripheral vessels (arrows) in lungs of normoxic WT (f) and $\mathrm{Hif} 2 \mathrm{\alpha}^{+/-}$mice $(\mathbf{g})$. Chronic hypoxia caused pulmonary vascular remodeling in WT mice, as revealed by the presence of fully muscularized vessels (arrows) (h and i), but not in Hif $2 \alpha^{+/-}$mice (arrows) (j). Bar $=50 \mu \mathrm{m}$ in all panels.

mice; $n=6 ; P=\mathrm{NS})$. After 4 weeks of hypoxia, hematocrit levels were comparably increased in both genotypes $(46 \% \pm 1 \%$ in 12 WT mice vs. $46 \% \pm 1 \%$ in 16 $H i f 2 \alpha^{+/-}$mice; $\left.P=\mathrm{NS}\right)$. These findings indicate that the reduced pulmonary hypertension in $H i f 2 \alpha^{+/-}$mice was not attributable to a lower vascular resistance caused by reduced erythropoiesis in hypoxia.

Role of HIF-2 $\alpha$ in pulmonary and cardiac gene expression. ET-1 may contribute to pulmonary vasoconstriction and pulmonary vascular remodeling by stimulating growth and proliferation of VSMCs (33), while ET-1 receptor blockade ameliorates pulmonary hypertension (4). Moreover, the promoter of the ET-1 gene harbors a HIF-binding site, and ET-1 is upregulated by hypoxia in vitro and in hypoxic lungs in vivo $(4,16)$. Therefore, pulmonary expression of ET-1 was determined by quantitative RT-PCR. No genotypic differences were observed in pulmonary ET-1 transcript levels in normoxia. After 6 days and 4 weeks of hypoxia, pulmonary ET-1 transcript levels were increased in WT but not in $\mathrm{Hif} 2 \mathrm{\alpha}^{+/-}$mice (Figure 1d). Measurements of ET-1 protein levels by ELISA confirmed that hypoxic upregulation of pulmonary ET-1 protein was impaired in Hif $2 \alpha^{+/-}$mice (pg ET-1/mg protein in normoxia and hypoxia, respectively: $10 \pm 2$ and $31 \pm 2$ in WT mice vs. $11 \pm 3$ and $19 \pm 3$ in Hif $2 \alpha^{+/-}$mice; $n=4 ; P<0.05$ in hypoxia). Because NO has a critical role in vasodilation of pulmonary vessels and inhibits VSMC growth (34), we also determined eNOS expression in the lungs. Pulmonary eNOS transcript levels were comparable in both genotypes under normoxia and after 6 days of hypoxia (mRNA copy number per 100 copies of HPRT mRNA in normoxia and hypoxia, respectively: $4.3 \pm 0.5$ and $3.7 \pm 0.1$ in WT mice vs. $3.2 \pm 0.4$ and $3.1 \pm 0.4$ in Hif $2 \alpha^{+/-}$mice; $n=6 ; P=\mathrm{NS}$ ). Western blot analysis (not shown) revealed that pulmonary eNOS protein was increased by hypoxia in WT mice (consistent with previous findings; ref. 35); pulmonary eNOS protein was upregulated to the same degree in $\mathrm{Hif} 2 \alpha^{+/-}$mice (data not shown), indicating that pulmonary eNOS expression in hypoxia is not regulated by HIF- $2 \alpha$.

ET-1 has also been implicated in cardiac hypertrophy (36). Cardiac ET-1 transcript levels were comparable under normoxia (mRNA copy number per 100 copies of HPRT mRNA: $90 \pm 10$ in WT mice vs. $100 \pm 10$ in Hif $2 \alpha^{+/}$ mice; $n=6 ; P=\mathrm{NS}$ ) but were upregulated to a higher level in WT than in $H i f 2 \alpha^{+/-}$mice after 4 weeks of hypoxia $\left(240 \pm 20\right.$ in WT mice vs. $160 \pm 30$ in Hif $2 \alpha^{+/-}$mice; $n=5$; $P<0.05)$. ELISA measurements demonstrated that hypoxic upregulation of cardiac ET-1 protein was also impaired in Hif $2 \alpha^{+/-}$mice (normoxia: $3.9 \pm 0.3 \mathrm{pg} / \mathrm{mg}$ protein in WT mice vs. $4.4 \pm 1.4 \mathrm{pg} / \mathrm{mg}$ protein in Hif $2 \alpha^{+/-}$mice; $n=4 ; P=\mathrm{NS}$; hypoxia: $7.1 \pm 0.3 \mathrm{pg} / \mathrm{mg}$ protein in WT mice vs. $5.1 \pm 1.5 \mathrm{pg} / \mathrm{mg}$ protein in Hif $2 \alpha^{+/-}$ mice; $n=4 ; P<0.05)$. Cardiac PDGF-B expression was also elevated by hypoxia in WT but not in $\mathrm{Hif} 2 \mathrm{\alpha}^{+/-}$mice (mRNA copy number per 100 copies of HPRT mRNA in normoxia: $0.5 \pm 0.1$ in WT mice vs. $0.5 \pm 0.1$ in $H_{i f} 2 \alpha^{+} /$ mice; $n=6 ; P=\mathrm{NS}$; mRNA copy number per 100 copies of HPRT mRNA in hypoxia: $1.2 \pm 0.3$ in WT mice vs. $0.5 \pm 0.1$ in Hif $2 \alpha^{+/-}$mice; $n=5 ; P<0.05$ ).

Role of HIF-2 $\alpha$ in catecholamine homeostasis. Expression of tyrosine hydroxylase, an essential gene for catecholamine biosynthesis, is upregulated by hypoxia (16). In addition, plasma catecholamines are increased during hypoxia and in patients with chronic obstructive pulmonary disease and/or pulmonary hypertension $(37,38)$. Since loss of HIF-2 $\alpha$ impairs fetal catecholamine production (22) and norepinephrine (NE) stimulates vasoconstriction of isolated pulmonary arteries (39) and pulmonary microvessels in rat lung explants (40), plasma NE levels were determined. Under normoxia, plasma NE levels were comparable in both genotypes $(0.5 \pm 0.1 \mathrm{ng} / \mathrm{ml}$ in WT mice vs. $0.6 \pm 0.1 \mathrm{ng} / \mathrm{ml}$ in Hif $2 \alpha^{+/-}$mice; $n=5$; $P=\mathrm{NS})$. Chronic hypoxia for 4 weeks elevated plasma NE 12-fold in WT mice but only 3.5 -fold in Hif $2 \alpha^{+/-}$mice $(5.8 \pm 1.5 \mathrm{ng} / \mathrm{ml}$ in WT mice vs. $2.2 \pm 0.5 \mathrm{ng} / \mathrm{ml}$ in Hif $2 \alpha^{+/-}$mice; $n=5 ; P=0.022$ ). After 4 days of hypoxia, 
when no pulmonary vascular remodeling was observed in WT mice (data not shown), plasma NE levels were already increased 3.5 -fold in WT mice $(1.8 \pm 0.3 \mathrm{ng} / \mathrm{ml})$, suggesting that the increased plasma NE levels in WT mice occurred prior to pulmonary vascular remodeling.

\section{Discussion}

The principal finding of this study is that heterozygous deficiency of HIF- $2 \alpha$ protects mice against pulmonary hypertension, RV hypertrophy, and dysfunction upon exposure to prolonged hypoxia. These findings unveil a critical role for HIF- $2 \alpha$ in pulmonary vascular remodeling, possibly by upregulation of ET-1 and NE.

Pulmonary vascular remodeling. Hypoxia caused a significant increase in neomuscularization of the pulmonary resistance vessels in WT mice, as evidenced by the increased fraction of pulmonary vessels that were completely covered by SMCs and contained both an IEL and a complete EEL. Since pulmonary veins exhibit minimal structural changes during chronic hypoxia (31), the increase in thick-walled pulmonary vessels likely corresponded to an increase in muscularized arterioles. Remarkably, vessel muscularization in $\mathrm{Hif} 2 \mathrm{\alpha}^{+/-}$mice after hypoxia was comparable to that in $H i f 2 \alpha^{+/-}$or WT mice after normoxia. Similar to heterozygous deficient $H i f 1 \alpha^{+/-}$mice (23), heterozygous deficient $\mathrm{Hif} 2 \mathrm{\alpha}^{+/-}$mice were also protected against pulmonary vascular remodeling. Although our data demonstrate that pulmonary hypertension during chronic hypoxia is mediated by HIF- $2 \alpha$, it remains to be determined whether the vascular remodeling is the result of a direct effect of HIF- $2 \alpha$ in the vessel wall or is caused, indirectly, by a HIF- $2 \alpha$-mediated pressure increase in the pulmonary arterioles. Another intriguing question is why the reduced HIF- $2 \alpha$ levels in Hif $2 \alpha^{+/-}$mice were sufficient to sustain embryonic development but not to induce pulmonary hypertension, suggesting that different thresholds of HIF- $2 \alpha$ expression may be required for distinct biological processes. A similar phenomenon has been previously observed in angiogenesis, where placental growth factor seems to affect pathological angiogenesis but not vascular development (41).

Pulmonary vascular remodeling is a complex, poorly understood process. Pulmonary vessels react to local hypoxia with constriction via upregulation of vasoactive substances as part of a natural response to normalize the oxygenation/perfusion ratio. When hypoxia is sustained and generalized, pulmonary vessels undergo significant structural changes involving neomuscularization and medial thickening of terminal bronchiolar and alveolar duct arterioles. Inhibitors of NAPDH oxidoreductases, which block HIF-1 $\alpha$ (16), reduce pulmonary vasoconstriction (42), suggesting that hypoxia-induced pulmonary vasoconstriction may be mediated by HIFs. Furthermore, pulmonary expression levels of ET-1, a wellknown HIF-1 $\alpha$ target gene (16), are increased in patients with pulmonary hypertension $(4,7)$, and inhibition of ET- 1 or its receptor prevents hypoxiainduced pulmonary hypertension and vascular remodeling (4). By causing vasoconstriction, ET-1 may initially increase the shear stress and initiate pulmonary vascular remodeling (7). Since ET-1 is known to stimulate growth of VSMCs $(4,33)$, it may also contribute to the muscularization of pulmonary vessels during hypoxia. As pulmonary ET-1 levels were markedly upregulated during hypoxia in WT but not in Hif $2 \alpha^{+/-}$mice, HIF- $2 \alpha$ may regulate the development of pulmonary hypertension at least in part via upregulation of ET-1. While ET-1 is a well-known target gene of HIF-1 $\alpha$ (16), our findings now demonstrate that expression of ET- 1 is also inducible by HIF- $2 \alpha$. This is not entirely surprising, since both HIF- $1 \alpha$ and HIF- $2 \alpha$ bind to the same HRE in the ET-1 promoter $(18,19)$ and HIF- $2 \alpha$ is abundantly expressed in the lung $(19,20)$. Whereas our findings suggest an involvement of HIF- $2 \alpha$ in pulmonary hypertension by regulation of ET- 1 expression, they obviously do not exclude that HIF- $2 \alpha$ regulates the expression of additional vasoactive substances.

$R V$ heart bypertrophy and dysfunction. Pulmonary hypertension leads to RV hypertrophy and dysfunction, ultimately progressing to RV failure (cor pulmonale) $(1,2)$. When WT mice were exposed for prolonged periods to hypoxia, $R V$ pressures were significantly increased and caused RV hypertrophy. RV pressures might even have been underestimated, as they were measured after equilibration of the mice to room air for 1 hour, which likely reduced or eliminated a hypoxia-induced vasoconstrictor response. WT mice also suffered signs of systolic and diastolic RV dysfunction, likely representing an insufficient myocardial adaptation to the prolonged increase in hemodynamic stress. In contrast, RV diastolic function was preserved, while RV systolic function improved in hypoxic Hif $2 \alpha^{+/-}$mice as compared with normoxic mice. This is remarkable since RV loading remained normal in hypoxic mutant mice, as suggested by the lack of remodeling of pulmonary vascular resistance vessels and the normal RV pressures. Possibly, cardiac function is enhanced in these mice to compensate for the hypoxemia and impaired oxygenation of peripheral tissues when maintained for prolonged periods in a low-oxygen environment. Expression of ET-1 and PDGF-B, previously implicated in cardiac hypertrophy $(36,43)$, was increased in hypertrophic hearts of hypoxic WT mice, suggesting that these molecules may have contributed, at least in part, to the hypertension-induced cardiomyocyte hypertrophy. In addition, ET-1 is known to induce hypertrophy with enhanced expression of muscle-specific genes in cultured rat cardiomyocytes in vitro (36). While HIF- $2 \alpha$ could directly stimulate ET-1 gene transcription, no HIF-binding site has thus far been identified in the PDGF-B promoter, suggesting that upregulation of PDGF-B occurs indirectly. However, the increased cardiac expression of ET-1 and/or PDGF-B may also have been a direct effect of the increased RV pressure. 
Catecholamine homeostasis. HIF- $2 \alpha$ has been implicated in the regulation of catecholamine biosynthesis during development (22), but a possible role during adult life has not been reported thus far. Hypoxia upregulated plasma NE levels 12-fold in WT mice but only 3.5fold in $\mathrm{Hif} 2 \mathrm{\alpha}^{+/-}$mice. Plasma NE levels are upregulated in patients with chronic obstructive pulmonary disease and/or pulmonary hypertension $(37,38)$. Since NE stimulates vasoconstriction of isolated pulmonary arteries (39) and of pulmonary microvessels in adult rat lung explants (40), and since NE is also known to stimulate growth of pulmonary SMCs (44), the impaired upregulation of NE under hypoxic conditions may also have contributed to the impaired pulmonary vascular remodeling and hypertension in $\mathrm{Hif} 2 \mathrm{\alpha}^{+/-}$mice. Although we cannot exclude that NE levels were upregulated due to an increase in pulmonary pressure, plasma NE levels were already elevated after 4 days of hypoxia in WT mice, i.e., prior to onset of significant pulmonary vascular remodeling. The observation that both WT and Hif $2 \alpha^{+/-}$mice had a similar increase in systolic RV pressure during acute hypoxia indicates that the acute hypoxic vasoconstriction response is unlikely to be mediated by HIF-2 $\alpha$. Instead, HIF- $2 \alpha$ is essential for upregulation of ET-1 and NE during chronic hypoxic conditions and thereby mediates SMC proliferation and pulmonary vascular remodeling.

Hematocrit. Yu et al. documented a delay in the development of polycythemia in Hifl $\alpha^{+/-}$mice (23). We did not observe any difference in hematocrit levels in $H i f 2 \alpha^{+/-}$mice after 4 weeks of hypoxia. Possibly, hypoxic induction of erythropoietin expression might be more dependent on HIF- $1 \alpha$ than on HIF- $2 \alpha$, at least under the present conditions. This contrasts with the significant role of HIF- $2 \alpha$ in the hypoxic upregulation of ET- 1 and NE and in the induction of pulmonary hypertension and vascular remodeling. While we cannot exclude that partial loss of HIF-2 $\alpha$ might have delayed polycythemia in the initial stage, the comparable hematocrit levels in combination with the impaired vascular remodeling in $\mathrm{Hif} 2 \mathrm{\alpha}^{+/-}$ mice after 4 weeks of hypoxia suggest that the lower vascular resistance in these mice was not attributable to the reduced hematocrit levels.

Weight loss. Both genotypes had comparable body weights at the start of the experiment (about $26 \mathrm{~g}$ ). Changes in body weight were more pronounced in WT than in Hif $2 \alpha^{+/-}$mice - both the weight gain in normoxia and the weight loss in hypoxia. As a result, WT mice weighed $18 \mathrm{~g}$ after 4 weeks of hypoxia and $32 \mathrm{~g}$ after 4 weeks of normoxia, while corresponding body weights of $\mathrm{Hif} 2 \mathrm{\alpha}^{+/-}$mice were $22 \mathrm{~g}$ in hypoxia and $29 \mathrm{~g}$ in normoxia. Another remarkable observation is that both $\mathrm{Hifl} \alpha^{+/-}$and $\mathrm{Hif} 2 \alpha^{+/-}$mice gained less weight during normoxia, while Hif $1 \alpha^{+/-}$mice, unlike Hif $2 \alpha^{+/-}$ mice, lost more weight than WT mice during hypoxia (23). These findings suggest that both HIFs have distinct roles. This may relate to their different cell-specific expression. Possibly, deficiency of HIF-1 $\alpha$ impairs glycolysis during hypoxia, thereby reducing the overall metabolism in Hifl $\alpha^{+/-}$mice. In contrast, we recently showed that HIF- $2 \alpha$ plays a less important role than HIF- $1 \alpha$ in hypoxic upregulation of glycolytic genes (26), suggesting that HIF-1 $\alpha$ could play a more important role than HIF- $2 \alpha$ in hypoxic regulation of particular processes influencing weight gain. Weight loss has also been documented in patients suffering from chronic obstructive pulmonary disease (45).

Medical significance. The role of HIF- $2 \alpha$ in the development of pulmonary hypertension and RV dysfunction may have clinical relevance. Overall, $H i f 2 \alpha^{+/-}$mice tolerated hypoxic stress much better than did WT mice, as they lost less weight, remained more active, and showed no pulmonary vascular remodeling or hypertension. Therefore, our data would encourage evaluation of the possible therapeutic potential of HIF- $2 \alpha$ inhibitors for this disease. Retrovirally mediated inhibition of HIFs, via blocking of the interaction of the cofactor p300 with HIF- $1 \alpha$ and HIF- $2 \alpha$, has been previously demonstrated to suppress tumor growth (46). Considering the limitations of current treatments of pulmonary hypertension $(2,3)$, inhibition of HIFs might be considered to prevent or reduce hypoxiainduced pulmonary hypertension. Since heterozygous deficiency of HIF- $2 \alpha$ already protected mice, partial inhibition of hypoxia-inducible factors may be therapeutically sufficient.

\section{Acknowledgments}

The authors thank S. Janssens (Center for Transgene Technology and Gene Therapy) for helpful discussion and A. Bouché, K. Bijnens, E. Gils, S. Jansen, L. Kieckens, A. Manderveld, K. Maris, T. Vancoetsem, A. Vandenhoeck, B. Vanwetswinkel, and S. Wyns (all from the Center for Transgene Technology and Gene Therapy) for technical assistance. This work was supported by a European BIOMED grant (no. PL963380) and a grant from the Interuniversitaire Attractiepolen.

1. Barbera, J.A., Peinado, V.I., and Santos, S. 2000. Pulmonary hypertension in COPD: old and new concepts. Monaldi Arch. Chest Dis. 55:445-449.

2. Hida, W., Tun, Y., Kikuchi, Y., Okabe, S., and Shirato, K. 2002. Pulmonary hypertension in patients with chronic obstructive pulmonary disease: recent advances in pathophysiology and management. Respirology. 7:3-13.

3. Barnes, P.J. 2000. Chronic obstructive pulmonary disease. N. Engl. J. Med. 343:269-280.

4. Chen, Y.F., and Oparil, S. 2000. Endothelin and pulmonary hypertension. J. Cardiovasc. Pharmacol. 35(4 Suppl. 2):S49-S53.

5. Durmowicz, A.G., and Stenmark, K.R. 1999. Mechanisms of structural remodeling in chronic pulmonary hypertension. Pediatr. Rev. 20:e91-e102.

6. Stenmark, K.R, and Mecham, R.P. 1997. Cellular and molecular mechanisms of pulmonary vascular remodeling. Annu. Rev. Physiol. 59:89-144.

7. Voelkel, N.F., and Tuder, R.M. 2000. Hypoxia-induced pulmonary vascular remodeling: a model for what human disease? J. Clin. Invest. 106:733-738

8. Fagan, K.A., et al. 1999. The pulmonary circulation of homozygous or heterozygous eNOS-null mice is hyperresponsive to mild hypoxia. J. Clin. Invest. 103:291-299.

9. Hoshikawa, Y., et al. 2001. Prostacyclin receptor-dependent modulation of pulmonary vascular remodeling. Am. J. Respir. Crit. Care Med. 164:314-318.

10. Geraci, M.W., et al. 1999. Pulmonary prostacyclin synthase overexpression in transgenic mice protects against development of hypoxic pulmonary hypertension. J. Clin. Invest. 103:1509-1515. 
11. Budts, W., et al. 2000. Aerosol gene transfer with inducible nitric oxide synthase reduces hypoxic pulmonary hypertension and pulmonary vascular remodeling in rats. Circulation. 102:2880-2885.

12. Eddahibi, S., et al. 2000. Attenuated hypoxic pulmonary hypertension in mice lacking the 5-hydroxytryptamine transporter gene. J. Clin. Invest 105:1555-1562.

13. Carmeliet, P., and Collen, D. 1998. Vascular development and disorders: molecular analysis and pathogenic insights. Kidney Int. 53:1519-1549.

14. Levi, M., et al. 2001. Deficiency of urokinase-type plasminogen activatormediated plasmin generation impairs vascular remodeling during hypoxia-induced pulmonary hypertension in mice. Circulation. 103:2014-2020.

15. Campbell, A.I., Zhao, Y., Sandhu, R., and Stewart, D.J. 2001. Cell-based gene transfer of vascular endothelial growth factor attenuates monocrotaline-induced pulmonary hypertension. Circulation. 104:2242-2248.

16. Semenza, G.L. 1999. Regulation of mammalian O2 homeostasis by hypoxia-inducible factor 1. Annu. Rev. Cell Dev. Biol. 15:551-578.

17. Carmeliet, P., et al. 1998. Role of HIF-1 $\alpha$ in hypoxia-mediated apoptosis, cell proliferation and tumour angiogenesis. Nature. 394:485-490.

18. Tian, H., McKnight, S.L., and Russell, D.W. 1997. Endothelial PAS domain protein 1 (EPAS1), a transcription factor selectively expressed in endothelial cells. Genes Dev. 11:72-82.

19. Ema, M., et al. 1997. A novel bHLH-PAS factor with close sequence similarity to hypoxia-inducible factor $1 \alpha$ regulates the VEGF expression and is potentially involved in lung and vascular development. Proc. Natl. Acad. Sci. U. S. A. 94:4273-4278.

20. Flamme, I., et al. 1997. HRF, a putative basic helix-loop-helix-PAS-domain transcription factor is closely related to hypoxia-inducible factor- $1 \alpha$ and developmentally expressed in blood vessels. Mech. Dev. 63:51-60.

21. Peng, J., Zhang, L., Drysdale, L., and Fong, G.H. 2000. The transcription factor EPAS-1/hypoxia-inducible factor $2 \alpha$ plays an important role in vascular remodeling. Proc. Natl. Acad. Sci. U. S. A. 97:8386-8391.

22. Tian, H., Hammer, R.E., Matsumoto, A.M., Russell, D.W., and McKnight, S.L. 1998. The hypoxia-responsive transcription factor EPAS1 is essential for catecholamine homeostasis and protection against heart failure during embryonic development. Genes Dev. 12:3320-3324.

23. Yu, A.Y., et al. 1999. Impaired physiological responses to chronic hypoxia in mice partially deficient for hypoxia-inducible factor $1 \alpha$. J. Clin. Invest. 103:691-696.

24. Shimoda, L.A., Manalo, D.J., Sham, J.S., Semenza, G.L., and Sylvester, J.T 2001. Partial HIF-1 $\alpha$ deficiency impairs pulmonary arterial myocyte electrophysiological responses to hypoxia. Am. J. Physiol. Lung Cell. Mol. Physiol. 281:L202-L208.

25. Compernolle, V., et al. 2002. Loss of HIF-2 $\alpha$ and inhibition of VEGF-signaling impair fetal lung maturation, while VEGF treatment prevents fatal respiratory distress in premature mice. Nat. Med. 8:702-710.

26. Brusselmans, K., et al. 2001. Hypoxia-inducible factor- $2 \alpha$ (HIF-2 $\alpha$ ) is involved in the apoptotic response to hypoglycemia but not to hypoxia. J. Biol. Chem. 276:39192-39196.

27. Hoit, B.D. 1998. Invasive hemodynamic studies in open and closed chest mice. In Cardiovascular physiology in the genetically engineered mouse. B.D. Hoit and R.A. Walsh, editors. Kluwer Academic Publishers. Norwell, Massachusetts, USA. 111-124.

28. Chen, E.P., Craig, D.M., Bittner, H.B., Davis, R.D., and Van Trigt, P. 1998 Pharmacological strategies for improving diastolic dysfunction in the setting of chronic pulmonary hypertension. Circulation. 97:1606-1612.
29. Steudel, W., et al. 1998. Sustained pulmonary hypertension and right ventricular hypertrophy after chronic hypoxia in mice with congenital deficiency of nitric oxide synthase 3. J. Clin. Invest. 101:2468-2477.

30. Champion, H.C., et al. 1999. Gene transfer of endothelial nitric oxide synthase to the lung of the mouse in vivo. Circ. Res. 84:1422-1432.

31. Roberts, J.D., Jr., Roberts, C.T., Jones, R.C., Zapol, W.M., and Bloch, K.D. 1995. Continuous nitric oxide inhalation reduces pulmonary arterial structural changes, right ventricular hypertrophy, and growth retardation in the hypoxic newborn rat. Circ. Res. 76:215-222.

32. Wiesener, M.S., et al. 2002. Widespread, hypoxia-inducible expression of HIF- $2 \alpha$ in distinct cell populations of different organs. FASEB J. 17:271-273.

33. Wort, S.J., Woods, M., Warner, T.D., Evans, T.W., and Mitchell, J.A. 2001. Endogenously released endothelin-1 from human pulmonary artery smooth muscle promotes cellular proliferation: relevance to pathogenesis of pulmonary hypertension and vascular remodeling. Am. J. Respir. Cell Mol. Biol. 25:104-110.

34. Nathan, C., and Xie, Q.W. 1994. Nitric oxide synthases: roles, tolls, and controls. Cell. 78:915-918.

35. Le Cras, T.D., and McMurtry, I.F. 2001. Nitric oxide production in the hypoxic lung. Am. J. Physiol. Lung Cell. Mol. Physiol. 280:L575-L582.

36. Ito, H., et al. 1991. Endothelin-1 induces hypertrophy with enhanced expression of muscle-specific genes in cultured neonatal rat cardiomyocytes. Circ. Res. 69:209-215.

37. Zaloga, G.P., et al. 1984. Increased circulating plasma norepinephrine concentrations in noncardiac causes of pulmonary hypertension. Crit. Care Med. 12:85-89.

38. Bratel, T., Wennlund, A., and Carlstrom, K. 2000. Impact of hypoxaemia on neuroendocrine function and catecholamine secretion in chronic obstructive pulmonary disease (COPD). Effects of long-term oxygen treatment. Respir. Med. 94:1221-1228.

39. Jin, N., Packer, C.S., English, D., and Rhoades, R.A. 1993. Inositol trisphosphate is involved in norepinephrine- but not in hypoxia-induced pulmonary arterial contraction. Am. J. Physiol. 264:L160-L164.

40. Davies, P., Maddalo, F., and Reid, L. 1984. The response of microvessels in rat lung explants to incubation with norepinephrine. Exp. Lung Res. 7:93-100

41. Carmeliet, P., et al. 2001. Synergism between vascular endothelial growth factor and placental growth factor contributes to angiogenesis and plasma extravasation in pathological conditions. Nat. Med. 7:575-583.

42. Jones, R.D., Thompson, J.S., and Morice, A.H. 2000. The NADPH oxidase inhibitors iodonium diphenyl and cadmium sulphate inhibit hypoxic pulmonary vasoconstriction in isolated rat pulmonary arteries. Physiol. Res. 49:587-596.

43. Suzuki, J., et al. 1999. Immunohistochemical analysis of platelet-derived growth factor-B expression in myocardial tissues in hypertrophic cardiomyopathy. Cardiovasc. Pathol. 8:223-231.

44. Nakaki, T., Nakayama, M., Yamamoto, S., and Kato, R. 1990. Alpha 1-adrenergic stimulation and beta 2-adrenergic inhibition of DNA synthesis in vascular smooth muscle cells. Mol. Pharmacol. 37:30-36.

45. Gross, N.J. 2001. Extrapulmonary effects of chronic obstructive pulmonary disease. Curr. Opin. Pulm. Med. 7:84-92.

46. Kung, A.L., Wang, S., Klco, J.M., Kaelin, W.G., and Livingston, D.M. 2000. Suppression of tumor growth through disruption of hypoxia-inducible transcription. Nat. Med. 6:1335-1340. 